\title{
ФОРМЫ ИНТЕРАКТИВНЫХ ПОДХОДОВ ПРИ ИЗУЧЕНИИ ДИСЦИПЛИНЫ «УПРАВЛЕНЧЕСКИЙ УЧЕТ»
}

\author{
(c) 2020 Лялькова Евгения Евгеньевна \\ кандидат экономических наук, доцент Департамента «Учет, анализ и аудит» \\ Финансовый университет при Правительстве РФ, Россия, Москва \\ E-mail: eelyalkova@fa.ru
}

Уровень заинтересованности в развитии управленческого учета в России очень высок. В статье рассматривается значение и роль дисциплины «Управленческий учет» при подготовке студентов экономических специальностей. Проводится сравнение дистанционного и классического очного обучения по рассматриваемой дисциплине. Статья содержит классификацию методов обучения. Рассмотрен конус обучения Эдгара Дейла, обоснована более высокая эффективность применения активных и интерактивных форм обучения. Представлены авторские методики интерактивных методов, в частности игр «Теория» и «Термины», применяемые автором при преподавании дисциплины «Управленческий учет». Подробно описана технология применение игр.

Ключевые слова: управленческий учет, дистанционное и очное обучение, интеллект-карта дисциплины, классификация методов обучения, конус обучения Эдгара Дейла, интерактивные методы обучения, использование игр в процессе изучения дисциплины «Управленческий учет».

Эффективная экономика может быть только при грамотном управлении экономическими субъектами. Основы навыков такого управления закладываются в ВУЗе, в дальнейшем закрепляются и развиваются на практике.

Успешное руководство компанией предполагает эффективное использование всех имеющихся в ней видов ресурсов: материальных, трудовых и финансовых, которые должны обеспечить желаемый финансовый результат. В современных условиях компании имеют хозяйственную и юридическую самостоятельность, что приводит к повышенной ответственности в системе экономических связей, а также к значимости функций управления предприятием. Управление невозможно без информационной системы, обеспечивающей принятие обоснованных и, в то же время, оперативных управленческих решений. Такой системой для руководства компании, несомненно, является система управленческого учета, которая нацелена не только на контроль со стороны руководства за использованием имеющихся ресурсов (активов предприятия), но и на текущую эффективность их использования.

Исторически в основу системы управленческого учета составляют данные, получаемые в процессе учета затрат по заготовлению, производству и сбыту продукции, товаров или выполнению работ, услуг.
В современных условиях, условиях информационной экономики в системе управленческого учета возможно использование не только финансовых критериев для оценки эффективности управления бизнес-процессами, которые сегодня все меньше удовлетворяют менеджеров и собственников организации. В частности, с их помощью нет возможности составлять точные прогнозы, они по большей части ориентированы на прошлое и содержат мало контрольной информации, необходимой для принятия стратегических решений. Наряду с этим, возможно использование и нефинансовых критериев. Поэтому в изучении дисциплины «Управленческий учет» заинтересованы не только студенты экономических специальностей, но также бухгалтеры, аудиторы и финансовые директоры. В учебном процессе одно из важных мест в развитии у студентов экономических специальностей управленческих знаний занимает предмет управленческий учет. При этом от форм, методов и эффективности его преподавания зависит усвоение студентами материала, формирование соответствующих навыков.

При изучении дисциплины «Управленческий учет» наряду с теоретическими знаниями должны формироваться и практические навыки по организации управленческого учета предпринимательской деятельности, подготовке и представлению полной информации 
топ-менеджерам, руководителям и другим заинтересованным внутренним пользователям по оперативному управлению предприятием, оперативному контролю и оценке результатов его работы, планированию и координации развития предприятия.

В связи с переходом на болонскую систему значительно сократился общий объём часов аудиторных занятий, при этом, увеличилось количество времени, отводимого на самостоятельную работу студента [1]. Поэтому преподаватели не имеют возможности присутствовать и участвовать в каждой учебной активности и вынуждены оптимизировать методы обучения в условиях ограниченности времени общения в аудитории, что стало предпосылкой разработки изложенных в настоящей статье предложений.

Преподавательскую деятельность можно рассматривать как процесс передачи знаний, навыков, умений, а также регулирование, контроль и оценку индивидуальной деятельности обучающихся. Эффективность работы преподавателя может измеряться теми знаниями, умениями, пониманием и компетентностью, который получил студент в процессе обучения.

Целью изучения дисциплины «Управленче- ский учет» является формирование у студентов теоретических знаний и практических навыков в области отражения и использования управленческой информации.

Перед началом обучения необходимо ознакомить студентов с перечнем изучаемых вопросов, видом контрольных мероприятий (таковыми могут быть курсовые и контрольные работы, тесты, зачет, экзамен и т.д.), системой оценки деятельности студентов и выставлением баллов.

Для укрупненного обзора изучаемых блоков дисциплины автор использует разработанную интеллект карту дисциплины, представленную на рис. 1.

В рамках дисциплины «Управленческий учет» применяется балльно-рейтинговая система оценки индивидуальной работы студентов. Текущий контроль осуществляется в течение семестра и представляет собой оценку знаний, полученных на лекционных и практических занятиях и в ходе самостоятельного изучения студентами учебного материала. Результаты текущего контроля преподаватель выставляет в ведомости, которую ведет в течение семестра. Преподаватель регулярно выставляет в ведомость текущего контроля количество баллов, по-

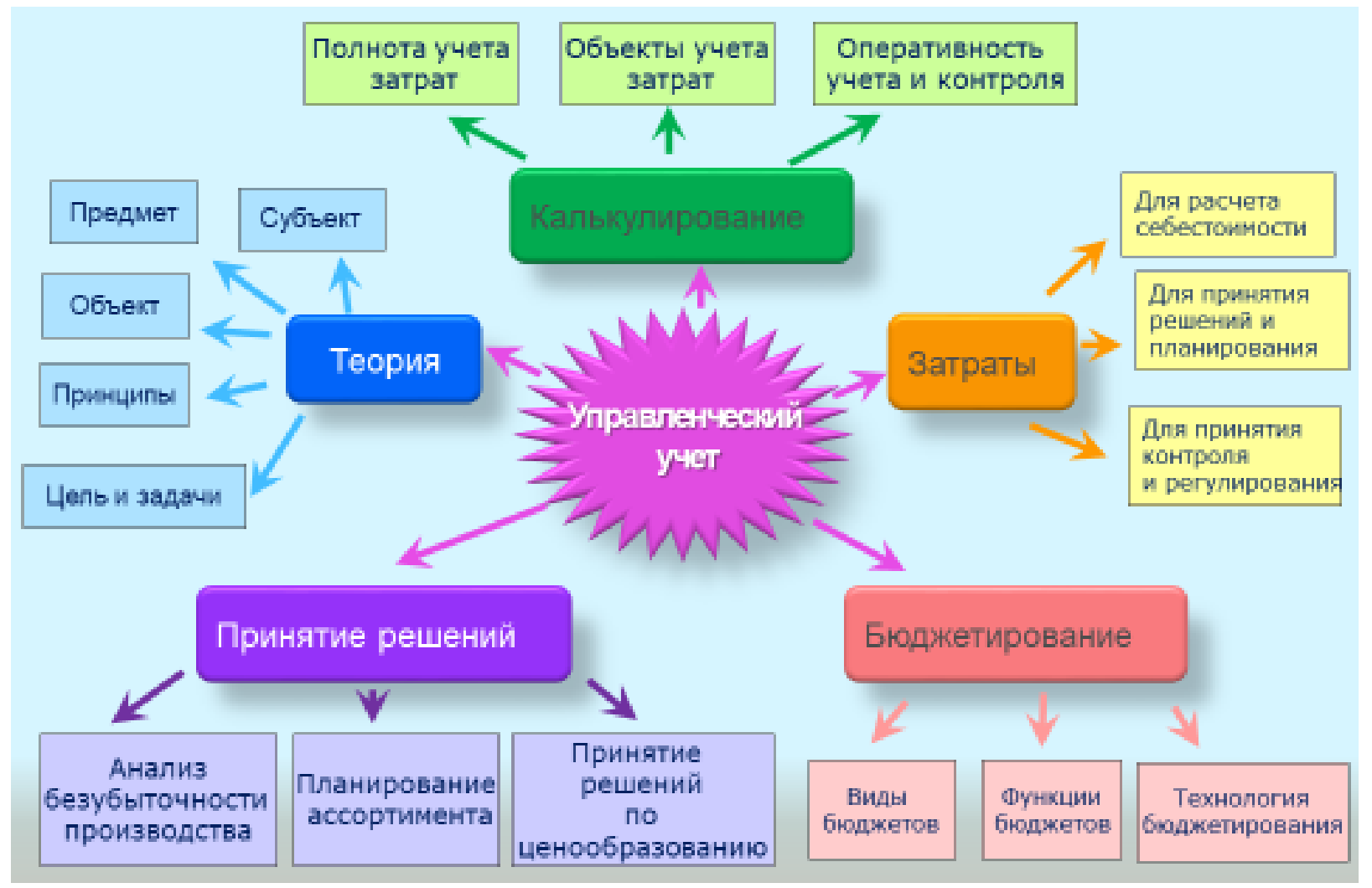

Рисунок 1. Интеллект-карта дисциплины «Управленческий учет» (разработано автором). 
лученных студентом при выполнении плановых учебных заданий, предусмотренных при изучении учебной дисциплины. По итогам работы для выставления итоговых оценок в Финансовом университете при Правительстве РФ используется следующая шкала соответствия между оценками, выставляемыми по многобалльной системе, и оценками по пятибалльной системе: «отлично» - 86-100 баллов; «хорошо» - 70-85 баллов; «удовлетворительно» - 50-69 баллов. В целях ознакомления студентов с системой оценивания отдельных видов активности и выведения итоговой оценки используется разработанная в приложении Microsoft Excel модель (Рис. 2).

Такой подход с первого занятия дает студентам представление о предстоящей работе по всему курсу обучения.

Наряду с этим нельзя не отметить, что на сегодняшний день научная мысль и практическая деятельность в сфере образования наработали огромное количество новых идей и практических воплощений. В условиях стремительного развития информационных технологий все больше набирает популярность дистанционное образование.

Многолетний опыт преподавания дисциплины «Управленческий учет» как дистанционно, так и очно, позволил сделать определенные выводы по положительным и негативным аспектам дистанционного образования. К положительным моментам можно отнести возможность для студентов обучаться в удобное время, в своем темпе, в любом оборудованном месте и без отрыва от основной деятельности. Также к положительному можно отнести и доступность учебных материалов, т.к. они предоставляются в электронном виде или высылаются по почте. Плюс ко всему дистанционное образование в целом дешевле очного. Также положительным является дополнительное виртуальное общение студента с преподавателем в удобное для обеих сторон время. В Финансовом университете такое общение реализуется через форум информационно-образовательного портала.

При современности и практическом удобстве данной формы, она имеет и объективные негативные стороны. Во-первых, это полное отсутствие личного контакта как учащихся между собой, так и с преподавателями. Поэтому такая форма обучения совершенно не способствует развитию коммуникабельности и навыков командной работы. Также студенты должны иметь очень высокую степень мотивации и самоорганизованности.

Во-вторых, при дистанционной форме обучения не имеется возможности применить некоторые весьма эффективные методики обучения, например, деловые игры, игры в команде. Помимо прочего, основным контрольным мероприятием, как правило, является прохождение тестов и выполнение контрольной работы. При этом идентифицирование личности, выполняющей эти виды работ затруднено.

Практика показывает, что по итогам обучения по такой форме, студенты при сдаче государственных экзаменов и защите диплома имеют достаточно низкий (в сравнении со студентами очной формы обучения) уровень знаний и невысокие результаты, хотя текущее их обучение было документально успешным.

По мнению автора, дистанционное обучение, несомненно, является прогрессивным, современным и весьма перспективным, однако, необходимо сохранять его баланс с классическим очным обучением, предусматривающее личное присутствие студента в аудитории и обеспечи-

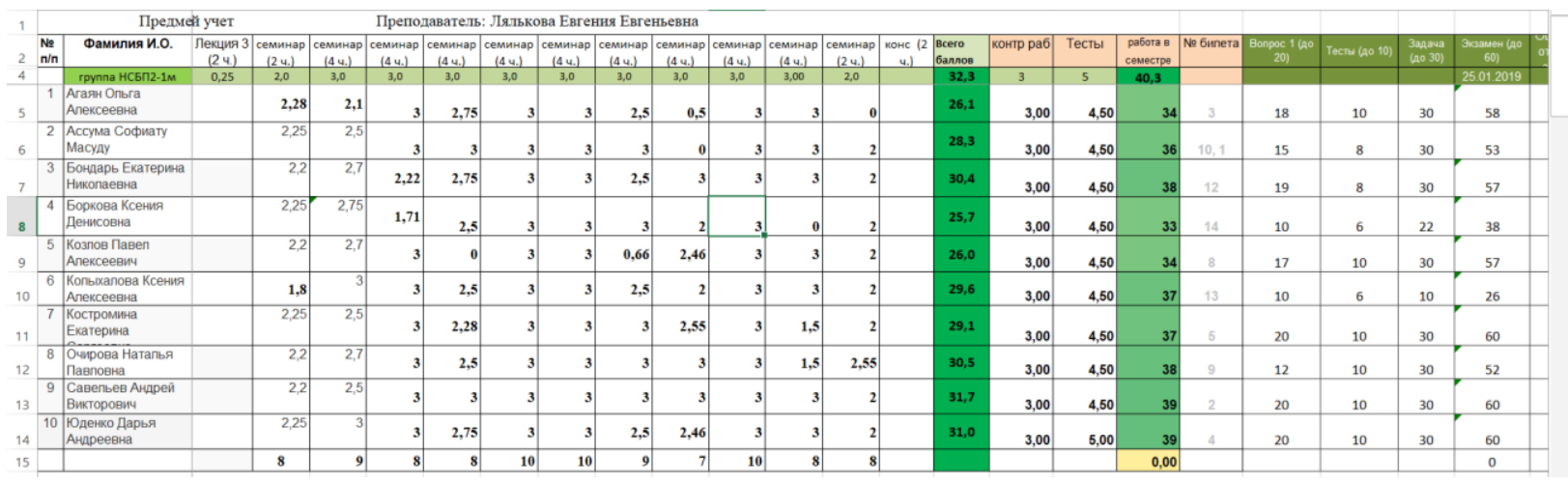

Рисунок 2. Модель оценивания активности студентов и выставления результативной оценки (разработано автором). 
вающее более высокую результативность как в формировании теоретических знаний, так и практических навыков.

Методы и приемы, используемые в процессе классического очного обучения, являются способами активного взаимодействия преподавателя и студента для осуществления совместной деятельности, которая направлена на достижение образовательных целей.

Классифицирование методов обучения применительно к дисциплине «Управленческий учет» осуществляется по признакам, представленным в табл.1 [2].

При этом методы обучения постоянно совершенствуются. К примеру, еще в 1969 году Эдгар Дейл (Edgar Dale) году выявил ряд эффективных способы обучения. Он преподавал ученикам один и тот же учебный материал, но разными способами, а потом анализировал их способности вспоминать изученную информацию после окончания обучения. Эдгар Дейл пришел к следующим выводам. Во-первых, слушать лекции или читать материалы по предмету - это наименее эффективный способ обучения. Во-вторых, наиболее эффективный способ - обучать других и использовать изучаемый материал в собственной жизни. Результаты своего исследования он представил в виде схемы «Конус обучения» (рис. 3).

Как видно из рисунка, наиболее эффективными способами обучения являются активные (интерактивные) методы проведения занятий. Интерактивные методы обучения нацелены на результативное взаимодействие в команде, на быстрое получение нового знания и формирование атмосферы сотрудничества. Интерактивный метод подразумевает под собой выполнение коллективной работы всеми участниками образовательного процесса.

В современном учебном процессе к таковым можно отнести следующие формы [3]:

- дискуссия - один из приемов учебной работы, в рамках которой студенты высказывают свое мнение по проблеме, заданной преподавателем;

- круглый стол - один из наиболее эффективных приемов для обсуждения сложных и актуальных вопросов в любой профессиональной среде, а также обмена опытом. Использование данного приема позволяет повысить эффектив-

Таблица 1. Классификация методов обучения дисциплине «Управленческий учет»

\begin{tabular}{|c|c|c|}
\hline $\begin{array}{l}\text { Классификационный } \\
\text { признак }\end{array}$ & Название метода & Краткое описание метода \\
\hline \multirow{3}{*}{$\begin{array}{l}\text { По источнику переда- } \\
\text { чи знаний }\end{array}$} & словесный & $\begin{array}{l}\text { предполагает использование в процессе обучения таких } \\
\text { форм вербальной коммуникации как: рассказ, объяснение, } \\
\text { беседа, дискуссия и т.д.; }\end{array}$ \\
\hline & $\begin{array}{l}\text { использование нагляд- } \\
\text { ных методов }\end{array}$ & $\begin{array}{l}\text { предполагает демонстрацию материала с помощью таблиц, } \\
\text { макетов, карт, компьютерных программ и др.; }\end{array}$ \\
\hline & $\begin{array}{l}\text { использование практи- } \\
\text { ческих методов }\end{array}$ & $\begin{array}{l}\text { методов предполагает выполнение различных упражнений } \\
\text { и лабораторных работ, решение задач, принятие участия в } \\
\text { дидактических и деловых играх и др. в процессе обучения }\end{array}$ \\
\hline \multirow{3}{*}{$\begin{array}{l}\text { По степени вклю- } \\
\text { ченности участников } \\
\text { образовательного } \\
\text { процесса }\end{array}$} & академический & $\begin{array}{l}\text { знания, навыки передаются от преподавателя к обучаемым } \\
\text { в готовом виде }\end{array}$ \\
\hline & активный & $\begin{array}{l}\text { предполагает получение знаний посредством самостоя- } \\
\text { тельной работы обучаемого }\end{array}$ \\
\hline & интерактивный & $\begin{array}{l}\text { способствует получению нового учебного знания } \\
\text { через совместную работу участников образовательного } \\
\text { процесса }\end{array}$ \\
\hline \multirow{5}{*}{$\begin{array}{l}\text { По способу передачи } \\
\text { информации в учеб- } \\
\text { ном процессе }\end{array}$} & прямое обучение & $\begin{array}{l}\text { преподаватель в доступной форме последовательно излага- } \\
\text { ет основные понятия, законы и принципы предмета }\end{array}$ \\
\hline & исследование & $\begin{array}{l}\text { предполагает вовлечение обучающихся в проблемную си- } \\
\text { туацию и самостоятельный поиск ответов }\end{array}$ \\
\hline & моделирование & $\begin{array}{l}\text { представляет собой участие в схематическом представле- } \\
\text { нии реальных жизненных ситуаций }\end{array}$ \\
\hline & совместное обучение & $\begin{array}{l}\text { предполагает работу обучающихся в группах над } \\
\text { определенной частью учебного материала }\end{array}$ \\
\hline & адаптивное обучение & $\begin{array}{l}\text { позволяет учесть индивидуальный уровень подготовки } \\
\text { обучаемых до начала учебного процесса и в самом процес- } \\
\text { се обучения }\end{array}$ \\
\hline
\end{tabular}




\begin{tabular}{|c|c|c|}
\hline $\begin{array}{c}\text { Спустя две недели у нас в } \\
\text { памяти обычно остается: }\end{array}$ & & $\begin{array}{c}\text { Степень вовлечения в } \\
\text { учебный процесс: }\end{array}$ \\
\hline \multirow{3}{*}{$\begin{array}{l}90 \% \text { того, что мы } \\
\text { говорим и делаем }\end{array}$} & Реальная работа & \multirow[t]{5}{*}{ Активная } \\
\hline & Имитация реального опыта & \\
\hline & Ролевая игра & \\
\hline \multirow{2}{*}{$\begin{array}{l}70 \% \text { того, что мы } \\
\text { говорим }\end{array}$} & Проведение бесед & \\
\hline & Участие в дискуссиях & \\
\hline \multirow{4}{*}{$\begin{array}{l}50 \% \text { того, что мы } \\
\text { видим и слышим }\end{array}$} & $\begin{array}{c}\text { Наблюдение за } \\
\text { реальным процессом }\end{array}$ & \multirow{7}{*}{ Пассивная } \\
\hline & Просмотр презентации & \\
\hline & $\begin{array}{c}\text { Наблюдение за } \\
\text { демонстрационным } \\
\text { процессом }\end{array}$ & \\
\hline & Просмотр кинофильма & \\
\hline $30 \%$ того, что мы видим & Просмотр иллюстраций & \\
\hline $20 \%$ того, что мы слышим & $\begin{array}{c}\text { Прослушивание } \\
\text { выступлений }\end{array}$ & \\
\hline $10 \%$ того, что читаем & Чтение & \\
\hline
\end{tabular}

Рисунок 3. конус обучения Эдгара Дейла

https://hr-portal.ru/blog/povyshenie-effektivnosti-obucheniya-s-pomoshchyu-konusa-edgara-deyla

ность усвоения учебного материала, а также способствует поиску решения в процессе диалога.

- метод кейс-стади - прием обучения, при котором студенты и преподаватели участвуют в непосредственном обсуждении деловых ситуаций или задач. Данный метод обучения дает возможность студенту самостоятельно принимать решение и обосновывать его.

- ролевая игра - это интерактивный метод, который позволяет обучаться на собственном опыте путем специально организованного и регулируемого “проживания” жизненной и профессиональной ситуации.

К примеру, одной из используемых автором методик при изучении дисциплины «Управленческий учет» является проведение различных игр, что является очень эффективным средством обучения. В зависимости от вида игры, студенты могут реализоваться в нетипичных для себя ролях. Их шаблон поведения отходит на второй план, и, фактически оставаясь в учебном процессе, они имеют возможность реализовать модели поведения финансовых директоров, бухгалтеров-аналитиков, менеджеров, управленцев и т.д.

Проиллюстрировать сказанное можно на примере двух игр: командной игры по теме «Теоретические основы управленческого учета» и игры «Термины» по теме «Учет затрат и калькулирование себестоимости продукции».

Цель проведения командной игры по теме «Теоретические основы управленческого учета» - закрепление знаний по теоретическим вопросам, которые были получены в ходе лекций и самостоятельного освоения материала. Для проведения выбираются три будущие капитана, которые по одному человеку набирают каждый свою команду. Расчётно, если в группе 15-21 
человек, в одной команде получится 5-7 участников. Студентам предлагаются вопросы, находящиеся на парте в равном удалении от команд. Один из участников каждого коллектива вытягивает вопрос и максимально быстро доносит его до остальных членов команды. Вот пример вопросов, обсуждаемых в игре:

«Определение и понятие управленческого учета (УУ)»

«История возникновения УУ как дисциплины»

«Пользователи УУ»

«Международное регулирование и ведущая организация»

«Элементы системы УУ»

«Цель и задачи, решаемые на базе Уу»

«Виды структурных подразделений в УУ»

«Методы, применяемые в УУ»

«Программы автоматизации УУ» и т.д.

Задача студентов как можно быстрее и правильнее ответить на поставленный вопрос. После каждого ответа команды правильный ответ преподавателю необходимо для его закрепления отразить на экране. Первая правильно ответившая команда получает 3 балла за ответ, вторая 2 , третья -1 . За каждый раунд каждая команда зарабатывает определенное количество баллов, которые по итогам складываются. Команда, набравшая в сумме наибольшее их количество, зарабатывает максимальное количество баллов, предусмотренных за данный семинар в целом и дальше по убыванию. Таким образом, у студентов есть прямая заинтересованность в изучении материала для его быстрого и правильного применения. Игра проходит динамично и интеллектуально и даже физически активно.

Вторая игра, о которой пойдет речь - «Термины» по теме «Учет затрат и калькулирование себестоимости продукции», не менее интересна и позитивно воспринимается студентами. Этот тип активности напоминает игру «Крокодил». Цель игры - формирование профессионального и практического категориального аппарата, грамотное, оперативное и эффективное использование терминологии по рассматриваемой теме.

Ход игры следующий. Таким же образом, как и в предыдущем варианте, группа делится на три команды. На стол выкладываются термины, которые студенты также не видят. В примерный перечень понятий могут входить: понятие себестоимости, попроцессный метод, понятие «передел», эквивалентное число готовых изделий, бюджетная ставка при позаказном методе учета затрат и калькулирования, стандарт-кост, система учета «директ-костинг», таргет -костинг, JIT (анг. Just-in-Time, Точно-в-срок, точно вовремя) и др.

Одна из команд вытягивает один из вопросов и, не называя того, что отмечено в записи напрямую, пытается охарактеризовать данное понятие другими словами. Две другие команды должны понять, о чем идет речь и назвать загаданный термин. Та команда, которая угадала, и та, которая объясняла, зарабатывают по одному баллу в общий счет своих команд. Следующий термин вытягивает угадавшая команда. По истечении нескольких раундов можно подвести итоги аналогичным образом с предыдущей игрой.

По результатам проведения перечисленных игр у студентов наблюдается высокая эффективность усвоения обсуждаемого материала, возрастает корректность его применения. Соответствующая игровая форма обучения дисциплине «Управленческий учет» обеспечивает также легкость восприятия студентами информации и их эмоциональную вовлеченность в изучение дисциплины.

Поскольку дисциплина «Управленческий учет» - комплексная и требующая для освоения от студентов существенных знаний и навыков, рассмотренная выше игровая форма обучения гармонично дополняет такие необходимые для преподавателя качества, как умение вести диалог со студенческой аудиторией, умение рассуждать и реагировать на поставленные вопросы обучающимися. Использование интерактивных видов активности и игр позволяет преподавателю не только лучше донести до студенческой аудитории свои теоретические знания, но и эффективнее сформировать у обучаемых практические навыки в области управленческого учета.

Заключительное занятие так же возможно проводить в форме тестирования для выявления итогового уровня подготовленности студента в зависимости от посещения им аудиторных занятий, выполнения практических заданий и самостоятельной работы. Тестирование - контроль знаний с помощью тестов с открытыми и закрытыми вопросами для текущей и промежуточной аттестации и самоконтроля.

В целом, методика преподавания экономических дисциплин, в том числе и управленческого учета, содержит многообразие взаимосвязанных методов, приемов и форм обучения 
экономическим процессам и предметам. Основной особенностью методики очного образования можно назвать то, что сам процесс обучения неразрывно связан с экономической жизнью общества и экономических субъектов и имеет ярко выраженный прикладной аспект. Для эффективного процесса обучения необходимо гармоничное сочетание теории и практики, в противном случае полученные знания и сделанные выводы могут быть поверхностными и упрощенными.

Реализация данных подходов именно в предмете управленческого учета объективна и эффективна, так как имеет благоприятную информационную базу. Предложенные нами подходы базируются на гармоничном сочетании классических подходов к преподаванию (лекции, курсовые и контрольные работы) и интерактивных, в том числе игровых методов. Благодаря последним эффективность учебного процесса повышается в теоретической части, а сам процесс обучения приобретает ярко выраженный практический характер.

\section{Библиографический список}

1. ОСОБЕННОСТИ ПРЕПОДАВАНИЯ УЧЕБНОЙ ДИСЦИПЛИНЫ «УПРАВЛЕНЧЕСКИЙ УЧЕТ» В ВЫСШЕЙ ШКОЛЕ Смирнова Ю.В. В сборнике: Высшее образование для XXI века: проблемы воспитания доклады и материалы XIV Международной научной конференции: в 2 частях. 2017. С. 258-263.

2. РЕАЛИЗАЦИЯ МЕЖДИСЦИПЛИНАРНЫХ СВЯЗЕЙ ПРИ ПОДГОТОВКЕ И ПРЕПОДАВАНИИ ПРОГРАММЫ «БУХГАЛТЕРСКИЙ УПРАВЛЕНЧЕСКИЙ УЧЕТ» ШУШПаНОВ С.А. В сборНИКе: РАЗВИТИЕ ТЕОРИИ И ПРАКТИКИ УПРАВЛЕНИЯ СОЦИАЛЬНЫМИ И ЭКОНОМИЧЕСКИМИ СИСТЕМАМИ МатерИалЫ ПяТоЙ международной научно-практической конференции. Ответственный за выпуск Н.Л. Рогалева. 2016. С. 56-59.

3. Методика преподавания бухгалтерского управленческого учета /Максимова Т.И., Трунова Т.А. //Коллективная монография «Развитие методологии управленческого учета и анализа в научно-исследовательских организациях».- Воронеж: Издательско-полиграфический центр «Научная книга», 2015. Источник: https:// www.rea.ru/ru/org/branches/voronezh/Pages/spisok-publikatsij-kafedry-bukhgalterskogo-ucheta-analiza-iaudita.aspx ๔ ФГБОУ ВО «РЭУ им. Г.В. Плеханова» 